\title{
Patchoulol Production with Metabolically Engineered Corynebacterium glutamicum
}

\author{
Nadja A. Henke ${ }^{1}{ }^{(\mathbb{D}}$, Julian Wichmann ${ }^{2}$, Thomas Baier ${ }^{2}$, Jonas Frohwitter ${ }^{1}$, Kyle J. Lauersen ${ }^{2}$ (), \\ Joe M. Risse ${ }^{3}$, Petra Peters-Wendisch ${ }^{1}$, Olaf Kruse ${ }^{2}$ and Volker F. Wendisch ${ }^{1, *}$ (iD \\ 1 Genetics of Prokaryotes, Faculty of Biology \& CeBiTec, Bielefeld University, D-33615 Bielefeld, Germany; \\ n.henke@uni-bielefeld.de (N.A.H.); jonas.frohwitter@uni-bielefeld.de (J.F.); \\ petra.peters-wendisch@uni-bielefeld.de (P.P.-W.) \\ 2 Algae Biotechnology \& Bioenergy, Faculty of Biology \& CeBiTec, Bielefeld University, D-33615 Bielefeld, \\ Germany; julian.wichmann@uni-bielefeld.de (J.W.); thomas.baier@uni-bielefeld.de (T.B.); \\ kyle.lauersen@uni-bielefeld.de (K.J.L.); olaf.kruse@uni-bielefeld.de (O.K.) \\ 3 Fermentation Technology, Technical Faculty \& CeBiTec, Bielefeld University, D-33615 Bielefeld, Germany; \\ jrisse@uni-bielefeld.de \\ * Correspondence: Volker.wendisch@uni-bielefeld.de; Tel.: +49-521-106-5611
}

Received: 26 March 2018; Accepted: 16 April 2018; Published: 17 April 2018

\begin{abstract}
Patchoulol is a sesquiterpene alcohol and an important natural product for the perfume industry. Corynebacterium glutamicum is the prominent host for the fermentative production of amino acids with an average annual production volume of $\sim 6$ million tons. Due to its robustness and well established large-scale fermentation, $C$. glutamicum has been engineered for the production of a number of value-added compounds including terpenoids. Both C40 and C50 carotenoids, including the industrially relevant astaxanthin, and short-chain terpenes such as the sesquiterpene valencene can be produced with this organism. In this study, systematic metabolic engineering enabled construction of a patchoulol producing $C$. glutamicum strain by applying the following strategies: (i) construction of a farnesyl pyrophosphate-producing platform strain by combining genomic deletions with heterologous expression of ispA from Escherichia coli; (ii) prevention of carotenoid-like byproduct formation; (iii) overproduction of limiting enzymes from the 2-C-methyl-D-erythritol 4-phosphate (MEP)-pathway to increase precursor supply; and (iv) heterologous expression of the plant patchoulol synthase gene PcPS from Pogostemon cablin. Additionally, a proof of principle liter-scale fermentation with a two-phase organic overlay-culture medium system for terpenoid capture was performed. To the best of our knowledge, the patchoulol titers demonstrated here are the highest reported to date with up to $60 \mathrm{mg} \mathrm{L}^{-1}$ and volumetric productivities of up to $18 \mathrm{mg} \mathrm{L}^{-1} \mathrm{~d}^{-1}$.
\end{abstract}

Keywords: patchoulol; Corynebacterium glutamicum; sesquiterpene; metabolic engineering; algae; Escherichia coli

\section{Introduction}

Terpenoids are a diverse group of natural compounds that can be found in all organisms with numerous roles including, but not limited to, signaling, communication, defense, electron transfer, membrane fluidity, and pigmentation [1]. Terpenoids, also known as isoprenoids, are composed of five carbon (C5) units of isopentenyl pyrophosphate (IPP) and its isomer dimethylallyl pyrophosphate (DMAPP). IPP and DMAPP are produced by either the 2-C-methyl-D-erythritol 4-phosphate (MEP) or the mevalonate (MVA) pathways. Both pathways are capable of producing the same IPP and DMAPP precursors and the MEP pathway is found in most bacteria as well as plant plastids, while the MVA pathway is found commonly in eukaryotes and archaea [1,2]. These building blocks are condensed by 
prenyltransferases to form larger carbon backbones $\left(C_{10}-C_{n}\right)$ that can be formed into the vast array of terpenoid molecules via the modular enzymatic reactions of the terpene synthases. Terpene backbones can also be functionalized by further down-stream enzymes such as cytochrome P450s, yielding the observed array of chemical diversity of terpenoid natural compounds [3].

The demand for naturally produced terpenoids is increasing due to increased consumer awareness and growing demand for naturally sourced materials in everyday products such as food, cosmetics, perfumes, and household chemicals. Although some terpenoids can be extracted from plant material, terpenoid production processes using bio-based microbial platforms are gaining attention as sustainable and economical alternatives. Terpenoid biosynthesis is inherently modular, with defined enzymatic steps leading from precursors to specific terpenoid products [3]. As all organisms contain the building blocks for terpenoid biosynthesis, it is possible to selectively transfer terpene synthases from organisms that naturally produce a desired compound into biotechnologically amenable hosts. Controlled microbial fermentation and production of terpenoids can have numerous benefits over harvesting and extraction from native organisms including containment, scalability, reliable product yield, shorter generation times, and minimizing environmental impacts from harvesting or agricultural cultivation.

Farnesyl pyrophosphate (FPP), the prenylated precursor of sesquiterpenoids (C15), is formed by condensation of DMAPP and two molecules of IPP by the enzyme farnesyl pyrophosphate synthase (FPPs). Sesquiterpenoid products are generated from FPP by sesquiterpene synthases. The sesquiterpenoid alcohol patchoulol is harvested from the leaves of the plant Pogostemon cablin, and is used as a component in perfumes, incense, and natural insect repellents [4]. P. cablin is traditionally cultivated in Indonesia and India where steam distillation of leaves is used to extract its essential oil, the main odor compound in this oil is the sesquiterpenoid alcohol patchoulol $[5,6]$. Patchouli oil is currently produced via traditional agriculture and steam distillation, $2.2-2.8 \mathrm{~kg}$ of patchouli oil can be extracted from $100 \mathrm{~kg}$ of dried patchouli leaves. This process lasts 8 hours and can consume 40 liters of kerosene [6]. As this process is energy and resource intensive, microbial fermentative processes for the production of patchoulol could minimize its environmental footprint and improve product yields. The conversion of FPP to patchoulol is mediated by a single enzyme, the patchoulol synthase (PcPS; PTS, uniprot: Q49SP3) [5,7], and heterologous expression of this enzyme has been used to produce this fragrance compound in several microbial hosts including Saccharomyces cerevisiae [8], the moss Physcomitrella patens [9] and the green microalga Chlamydomonas reinhardtii [10]. Mixtures of sesquiterpenes and alcohols present in patchouli oil obtained by fermentation have been marketed (e.g., by Firmenich). It was shown that overproduction of the patchoulol synthase in Escherichia coli produced several sequiterpenes besides patchoulol [5]. Thus, this product promiscuity could find suitable applications in protein engineering towards other sequiterpenes and the specificity for production of patchoulol itself could be a target for further enzyme engineering studies for the PcPS.

The Gram-positive bacterium Corynebacterium glutamicum is the workhorse of industrial biotechnology for amino acid production and is already cultivated in industrial processes for the production of L-glutamate and L-lysine. Fermentations with this host are characterized by robust growth, high cell densities and high volumetric productivities [11-13]. The annual production volume of L-glutamate and L-lysine in industrial processes with C. glutamicum is estimated to reach 6 million tons in 2023 [14]. Currently, industrial production plants for C. glutamicum cultivation are found worldwide indicating that engineering of this organism for expanded profiles of natural products has great biotechnological and commercial value potentials. C. glutamicum is not only a natural L-glutamate producer, but also accumulates a yellow carotenoid, decaprenoxanthin, in its membranes $[15,16]$. The carotenoid biosynthesis of $C$. glutamicum has been analyzed in more detail over the last years [15]. Based on this knowledge, C. glutamicum has been engineered for production of a range of high value terpenoids including short-chain terpenoids $[17,18]$ and various $C 40$ and $C 50$ carotenoids $[19,20]$. Besides gene deletion, integration and overexpression, also other methodologies such as regulator engineering [21], general transcription machinery engineering [22] and on-demand 
gene expression with photocaged-IPTG [18] were successfully demonstrated in this host to develop terpenoid overproducing strains. Furthermore, coproduction of the terpenoid astaxanthin and the amino acid L-lysine by a single C. glutamicum strain was established [23]. The coproduction of two value-added compounds represents a novel fermentation strategy in which a biomass-bound and a secreted substance were simultaneously produced during a single fermentation run. This example indicates the great volumetric productivity potential of engineered C. glutamicum for feed market applications [23].

In this work, we seek to expand the product profile range of $C$. glutamicum by engineering this organism for the production of the sesquiterpenoid perfume product patchoulol. Here, patchoulol production was achieved by combining construction of an FPP-producing platform strain, wherein carotenoid-like byproduct formation was prevented, with overproduction of rate-limiting MEP pathway enzymes. This strain was used for heterologous expression of the P. cablin patchoulol synthase (PcPS) and patchoulol production as well as a proof-of-principle liter-scale bioreactor fermentation with product capture using a two-phase organic solvent-culture overlay were demonstrated.

\section{Materials and Methods}

\subsection{Bacterial Strains, Media and Growth Conditions}

The strains and plasmids used in this work are listed in Table 1. C. glutamicum ATCC 13032 [24] was used as the parental strain for all metabolic engineering approaches. Pre-cultivation of $C$. glutamicum strains was performed in BHI/LB medium (Carl Roth, Karlsruhe, Germany) with 50 mM glucose. For main cultivation in CGXII minimal medium [25], these pre-cultivated cells were washed once with CGXII medium without carbon source and inoculated to an initial $O D_{600}$ of $1.100 \mathrm{mM}$ glucose was added as carbon and energy source. Standard cultivations of $C$. glutamicum were performed at $30^{\circ} \mathrm{C}$ in a volume of $20 \mathrm{~mL}$ in $100 \mathrm{~mL}$ flasks without baffles shaking at $120 \mathrm{rpm}$. The $O D_{600}$ was measured in dilutions using a Shimadzu UV-1202 spectrophotometer (Duisburg, Germany). For capturing of the volatile patchoulol $10 \%(v / v)$ of dodecane was added to the main culture [17]. E. coli DH5 $\alpha$ was used as host for all cloning aspects and cultivated in LB medium at $37^{\circ} \mathrm{C}$ overnight. When appropriate, tetracyclin, spectinomycin or kanamycin were added in concentrations of 5, 100 and $25 \mu \mathrm{g} \mathrm{mL} \mathrm{m}^{-1}$, respectively. Gene expression was induced by addition of $1 \mathrm{mM}$ IPTG to the main culture.

Table 1. Strains and plasmids used in this study.

\begin{tabular}{|c|c|c|}
\hline STRAIN; PLASMID & Relevant Characteristics & Reference \\
\hline \multicolumn{3}{|c|}{ Corynebacterium glutamicum STRAINS } \\
\hline WT & Wild type, ATCC 13032 & [24] \\
\hline$\Delta c r t E \Delta i d s A$ & crtE (cg0723) and idsA (cg2384) deletion mutant of ATCC 13032 & [17] \\
\hline$\Delta c r t O P \triangle i d s A \Delta c r t B 2 I^{\prime} I 2$ & $\begin{array}{c}\text { crtOP (cg0717- cg0723), idsA (cg2384) and crtB2I'I2 (cg2668-cg2672) deletion } \\
\text { mutant of ATCC } 13032\end{array}$ & this work \\
\hline PAT1 & $\Delta c r t E \Delta i d s A(\mathrm{pECXT}-i s p A-P c P S)(\mathrm{pEKEx} 3)$ & this work \\
\hline PAT2 & $\Delta c r t O P \triangle i d s A \Delta c r t B 2 I^{\prime} I 2(\mathrm{pECXT} i s p A-P c P S)(\mathrm{pVWEx} 1)$ & this work \\
\hline PAT3 & $\Delta c r t O P \Delta i d s A \Delta c r t B 2 I^{\prime} I 2$ (pECXT_ispA-PcPS)(pVWEx1_dxs-idi) & this work \\
\hline \multicolumn{3}{|l|}{ OTHER STRAINS } \\
\hline Escherichia coli $\mathrm{DH} 5 \alpha$ & 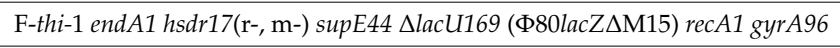 & [26] \\
\hline \multicolumn{3}{|l|}{ PLASMIDS } \\
\hline pOpt_PcPS & $\begin{array}{l}\text { Shuttle vector containing PcPS from Pogostemon cablin codon-optimized for } \\
\text { Corynebacterium glutamicum (gene synthesis) (Uniprot Q49SP3) }\end{array}$ & this work \\
\hline pEC-XT99A (pEC-XT) & Tet $^{\mathrm{R}}, P_{\text {trc }}$ lacl $^{\top}$, pGA1 ori $V_{C g}$, C. glutamicum $/ E$. coli expression shuttle vector & [27] \\
\hline pEC-XT_ispA-PcPS & $\begin{array}{l}\text { pEC-XT derivative for IPTG-inducible expression of isp A from E. coli and } \\
\text { codon-optimized PcPS from P. cablin (Uniprot Q49SP3) containing an } \\
\text { artificial ribosome binding site }\end{array}$ & this work \\
\hline pEKEx3 & Spec $^{\mathrm{R}}, P_{\text {tac }}$ lac ${ }^{q}, \mathrm{pBL1}$ ori $V_{C g}$, C. glutamicum $/$ E. coli expression shuttle vector & [28] \\
\hline
\end{tabular}


Table 1. Cont.

\begin{tabular}{|c|c|c|}
\hline STRAIN; PLASMID & Relevant Characteristics & Reference \\
\hline \multicolumn{3}{|l|}{ PLASMIDS } \\
\hline pEKEx3_araBAD & $\begin{array}{l}\text { pEKEx3 derivative for IPTG-inducible expression of the araBAD operon } \\
\text { from E. coli containing an artificial ribosome binding site }\end{array}$ & this work \\
\hline pEKEx3_xylAB & $\begin{array}{c}\text { pEKEx3 derivative for IPTG-inducible expression of } x y l A \text { from Xanthomonas } \\
\text { campestris and } x y l B \text { from C. glutamicum containing an artificial ribosome } \\
\text { binding site }\end{array}$ & [29] \\
\hline pVWEx1 & $\begin{array}{c}\mathrm{Km}^{\mathrm{R}}, P_{\text {tac }} \mathrm{lacl}^{q}, \mathrm{pHM} 519 \text { ori }_{\mathrm{Cg}}, \mathrm{C} . \text { glutamicum } / \text { E. coli expression } \\
\text { shuttle vector }\end{array}$ & {$[30]$} \\
\hline pVWEx1_dxs-idi & $\begin{array}{l}\text { pVWEx1 derivative for IPTG-inducible expression of } d x s \text { (cg2083) and idi } \\
\text { (cg2531) from C. glutamicum containing an artificial ribosome binding site }\end{array}$ & [18] \\
\hline pK19mobsacB & $\begin{array}{l}\mathrm{Km}^{\mathrm{R}} ; \text { E. coli/C. glutamicum shuttle vector for construction of insertion and } \\
\text { deletion mutants in C. glutamicum }\left(\mathrm{pK} 18 \operatorname{ori}_{E c} \operatorname{sacB} l a c Z \alpha\right)\end{array}$ & [31] \\
\hline pK19mobsacB $\Delta c r t E$ & pK19mobsacB with a crtE (cg0723) deletion construct & [17] \\
\hline pK19mobsacB $\triangle i d s A$ & pK19mobsacB with a $i d s A$ (cg2384) deletion construct & [17] \\
\hline pK19mobsacB $\Delta c r t O P$ & pK19mobsacB with a crtOP (cg0717-cg0723) deletion construct & this work \\
\hline pK19mobsacB $\Delta c r t B 2 I^{\prime} I 2$ & pK19mobsacB with a crtB2I'I2 (cg2668-cg2672) deletion construct & this work \\
\hline
\end{tabular}

\subsection{Recombinant DNA Work}

Plasmids were constructed with Gibson assembly [32] or classical restriction and ligation. PCR-generated fragments (All-in HiFi, highQu, Kraichtal, Germany) were assembled into isolated plasmids (Plasmid GeneJET Miniprep kit, Thermo Fisher Scientific, Schwerte, Germany) that were linearized by restriction. Oligonucleotides used in this study were obtained from Metabion (Planegg/Steinkirchen, Germany) and are listed in Table 2. Standard reactions like restriction, and PCR were performed as described previously [33]. If applicable, PCR products were purified using the PCR clean-up and gel extraction kit (Macherey-Nagel, Düren, Germany). For transformation of E. coli $\mathrm{DH} 5 \alpha$, the $\mathrm{RbCl}$ method was used and C. glutamicum was transformed via electroporation [34] at $2.5 \mathrm{kV}, 200 \Omega$, and $25 \mu \mathrm{F}$. Vector construction was confirmed by sequencing of cloned inserts.

Table 2. Oligonucleotides used in this study.

\begin{tabular}{|c|c|}
\hline Strain & DNA Sequence \\
\hline crtOP-A & AAAACCCGGGTAGCTCCATATAACGTGCCG \\
\hline crtOP-B & СССАТССАСТАAАСТTAAACAGATTGTCATGCСАTTGTCCAT \\
\hline crtOP-C & TGTTTAAGTTTAGTGGATGGGACGATACTGCTAATAGCAATTCATCAGATATAA \\
\hline crtOP-D & AAAACCCGGGATGTGTGGGAGGCTTCGC \\
\hline crtOP-E & GTGACCATGAGGGCGAAAGC \\
\hline crtOP-F & AAAACAATGCGCAGCGCA \\
\hline crtB2I'I2-A & AAAACCCGGGGTCAGTGCTGTCATCGGTAC \\
\hline crtB2I'I2-B & CCCATCCACTAAACTTAAACAATCTTGCTGATCAGCCAC \\
\hline crtB2I'I2-C & TGTTTAAGTTTAGTGGATGGGAACAGTGTGGATCGGACTTAA \\
\hline crtB2I'I2-D & AAAACCCGGGCTGCATGAATGTTGGTGAAC \\
\hline crtB2I'I2-E & CGGACTTGATGCTGCAGC \\
\hline crtB2I'I2-F & TGAGCCGCAACCAATTGAAG \\
\hline PcPS-fw & AACTGCCACACGAACGAAAGGAGGCCCTTCAGATGGAGCTGTACGCCCAGAG \\
\hline PcPS-rv & GCATGCCTGCAGGTCGACTCTAGAGGATCTTAGCCGCTGCCGTAGGG \\
\hline$i s p A-\mathrm{fw}$ & ATGGAATTCGAGCTCGGTACCCGGGGAAAGGAGGCCCTTCAGATGGACTTTCCGCAGCAACTCG \\
\hline ispA-rv & GTTCGTGTGGCAGTTTTATTTATTACGCTGGATGATGTAGTCC \\
\hline $\operatorname{araBAD}-\mathrm{fw}$ & TGCAGGTCGACTCTAGAGGAAAGGAGGCCCTTCAGATGGCGATTGCAATTGGCCT \\
\hline araBAD-rv & GAGCTCGGTACCCGGGGATCTTACTGCCCGTAATATGCCT \\
\hline pEC-XT fw & AATACGCAAACCGCCTCTCC \\
\hline pEC-XT rv & TACTGCCGCCAGGCAAATTC \\
\hline
\end{tabular}

\subsection{Deletion and Exchange Mutagenesis in the Genome of Corynebacterium glutamicum}

For targeted deletion of the carotenogenic operons (cg0717-cg0723 and $\operatorname{cg} 2668-\operatorname{cg} 2672)$, crtE (cg0723) and idsA (cg2384), the suicide vector pK19mobsacB was used [31]. Genomic regions flanking the corresponding genes/operons were amplified from genomic DNA of C. glutamicum WT 
using primer pairs $\mathrm{A} / \mathrm{B}$ and $\mathrm{C} / \mathrm{D}$ (Table 2), respectively. The resulting amplificates were cloned into pK19mobsacB via Gibson method resulting in the construction of deletion vectors (Table 1). Deletions were carried out via two-step homologous recombination as well as the selection for the first and second recombination events were carried out as described previously [25]. Successful removals of genes or operons were verified by PCR analysis of the constructed mutants using primer pair E/F (Table 2).

\subsection{Fermentation of Corynebacterium}

A bioreactor with a total volume of $3.7 \mathrm{~L}$ and a working volume of $2.0 \mathrm{~L}$ was used for batch and fed-batch fermentations (KLF, Bioengineering AG, Switzerland). The stirrer axis was equipped with three six-bladed rushton turbines in a distance of $6 \mathrm{~cm}, 12 \mathrm{~cm}$, and $18 \mathrm{~cm}$ from the bottom. The relative dissolved oxygen saturation in the medium (rDOS) (Mettler-Toledo, Greifensee, Switzerland) and $\mathrm{pH}$ (Hamilton, Switzerland) were monitored with electrodes. The $\mathrm{pH}$ was kept at 7.0 by automated addition of $\mathrm{KOH} 4 \mathrm{M}$ and $10 \%(w / w)$ phosphoric acid. The initial volume of the fermentations was $2 \mathrm{~L}$. For feeding approximately $730 \mathrm{~mL}$ volume was added, depending on the $r D O S$. Fermentations were performed with 0.2 bar overpressure and an aeration rate of $2 \mathrm{NL} \mathrm{min}^{-1}$. The initial stirrer frequency was set to $200 \mathrm{~min}^{-1}$ and speed was increased in steps of $2 \%$ when $r D O S$ profile felt below $30 \%$ (fed-batch) or $60 \%$ (batch), respectively.

Struktol ${ }^{\circledR}$ was added manually as an antifoam reagent. For the fed-batch procedure the feeding profile was activated when the $r D O S$ was about $60 \%$ and stopped when $r D O S$ felt below $60 \%$. Samples were taken regularly and were stored at $4{ }^{\circ} \mathrm{C}$ until further use. Plasmid-driven gene expression was induced in the exponential growth phase $(t=5 \mathrm{~h})$. Capturing of patchoulol was conducted through a dodecane overlay that was applied 5 (batch) or 25 (fed-batch) hours after inoculation.

The fermenters were inoculated with a fresh overnight culture grown at $30{ }^{\circ} \mathrm{C}$ and $120 \mathrm{rpm}$ (amplitude: $2.5 \mathrm{~cm}$ ) to an initial $O D$ of $\sim 1$. The preculture medium contained: $13.6 \mathrm{~g} \mathrm{~L}^{-1}$ soypeptone, $7 \mathrm{~g} \mathrm{~L}^{-1}$ yeast extract, $2.5 \mathrm{~g} \mathrm{~L}^{-1} \mathrm{NaCl}, 2.3 \mathrm{~g} \mathrm{~L}^{-1} \mathrm{~K}_{2} \mathrm{HPO}_{4}, 1.5 \mathrm{~g} \mathrm{~L}^{-1} \mathrm{KH}_{2} \mathrm{PO}_{4}, 0.14 \mathrm{~g} \mathrm{~L}^{-1} \mathrm{MgSO}_{4} \cdot \mathrm{H}_{2} \mathrm{O}$, $40 \mathrm{~g} \mathrm{~L}^{-1}$ D-glucose monohydrate, $25 \mathrm{mg} \mathrm{L}^{-1}$ tetracycline, and $25 \mathrm{mg} \mathrm{L}^{-1}$ kanamycin. The fermentation was performed on the basis of the same medium. Feeding medium contained $300 \mathrm{~g} \mathrm{~L}^{-1} \mathrm{D}$-glucose monohydrate and $75 \mathrm{~g} \mathrm{~L}^{-1}$ yeast extract.

\subsection{Patchoulol Capture and Quantification}

The clean dodecane supernatants were analyzed via GC-MS using a TraceGC gas chromatograph (Thermo Scientific, Waltham, MA, USA) and ITQ ion trap mass spectrometer (Thermo Scientific, Waltham, Massachusetts, USA equipped with a AS 3000 autosampler (Thermo Scientific, Schwerte, Germany). As a column system a $30 \mathrm{~m} \times 0.25 \mathrm{~mm}$ VF- $5 \mathrm{~ms}$ column coated with $0.25 \mu \mathrm{m}$ of $5 \%$ diphenyl and $95 \%$ dimethylsiloxane (Varian $\mathrm{GmbH}$, Darmstadt, Germany) was used. Temperature profile was set as the following: injector $\left(250^{\circ} \mathrm{C}\right)$, interface $\left(250^{\circ} \mathrm{C}\right)$ and ion source $\left(220^{\circ} \mathrm{C}\right) .1 \mu \mathrm{L}$ of sample was injected in splitless mode. A constant flow of $1 \mathrm{~mL} \mathrm{~min}^{-1}$ helium was used as a carrier gas. The oven temperature profile was set as the following: $80^{\circ} \mathrm{C}$ for one minute, then raised to $120^{\circ} \mathrm{C}$ at $10{ }^{\circ} \mathrm{C}$ $\min ^{-1}$, followed by $3^{\circ} \mathrm{C} \mathrm{min}^{-1}$ to $160^{\circ} \mathrm{C}$, and further to $270{ }^{\circ} \mathrm{C}$ at $10^{\circ} \mathrm{C} \mathrm{min}{ }^{-1}$, which was held for $2 \mathrm{~min}$. Mass spectra were recorded after the dodecane peak eluted (12 $\mathrm{min}$ ) using a scanning range of $50-750 \mathrm{~m} / \mathrm{z}$ at 20 scans s$^{-1}$. Chromatograms were evaluated with Xcalibur software version 2.0.7 (Thermo Scientific, Germany). The NIST 05 library (National Institute of Standards and Technology, Gaithersburg, MD; ThermoFinnigan) was used to identify substances for which no standard was available. Standard calibration curves in the range of $1-450 \mu \mathrm{M}$ (or 0.5-100 $\mathrm{mg} \mathrm{L}^{-1}$ ) patchoulol in dodecane were used to quantify the amount of patchoulol $\left(\mathrm{R}^{2} \approx 0.99\right)$. $250 \mu \mathrm{M} \alpha$-humulene was applied in each sample as internal standard. Extracted-ion chromatograms (XIC) with mass ranges of 93.00 ( $\alpha$-humulene), 138.50 and 222.00 (patchoulol) were used (see Figure S2). 


\section{Results}

\subsection{Patchoulol Production in Shake Flasks with Metabolically Engineered Corynebacterium glutamicum}

C. glutamicum possesses two genes encoding GGPP synthases (Figure 1) with ids $A$ encoding the major GGPPS. Their biochemical characteristics and mutant studies revealed that primarily GGPP is formed by ids $A$ and $c r t E$ [35]. Therefore, the deletion mutant $\triangle c r t E \Delta i d s A$ derived from C. glutamicum wild type ATCC 13032 that was already employed for successful production of short-chain terpenoids $[17,18]$ was used here as the base strain for patchoulol production (Table 3).

a)

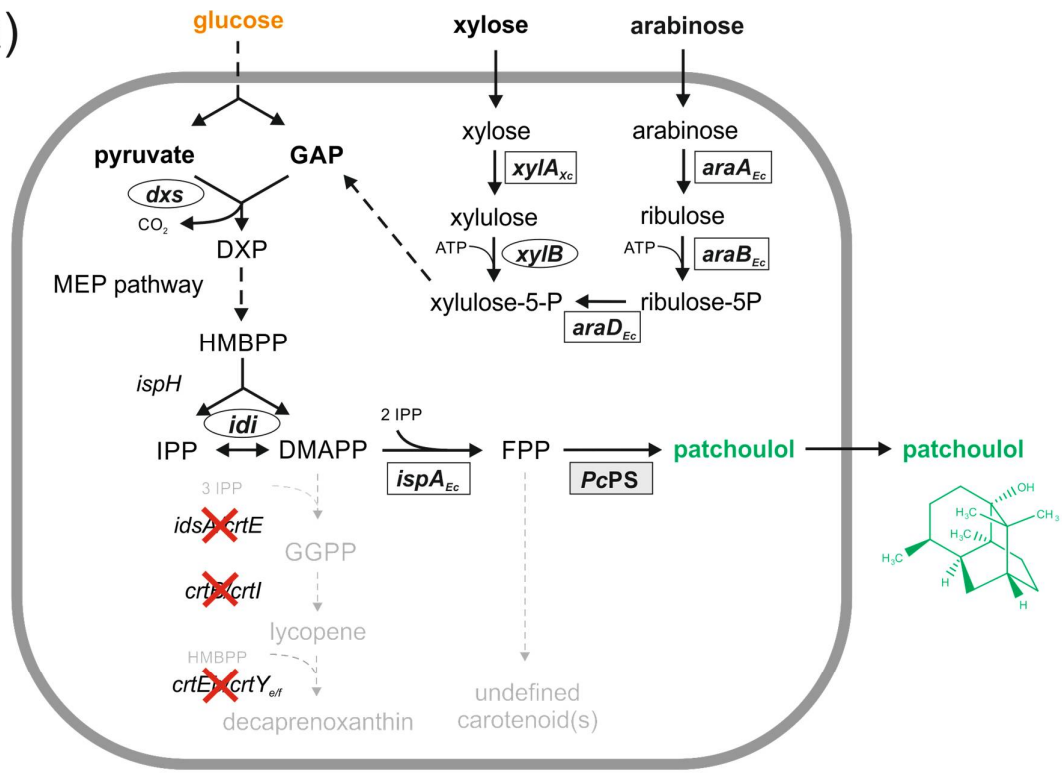

b)

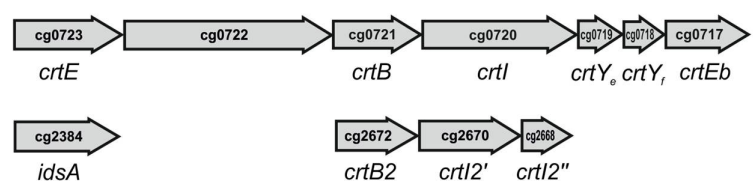

Figure 1. Patchoulol production by engineered Corynebacterium glutamicum. (a) Schematic representation of the patchoulol pathway in recombinant C. glutamicum. Overexpressed genes are in bold, endogenous genes are in circles, heterologous genes are boxed (clear background for bacterial origin and shaded background for eukaryotic origin), genes deletions are indicated by red crosses, gene names are indicated next to the reactions they catalyze, single reaction are represented by arrows, pathways with more than one reaction by dashed arrows. Abbreviations: $d x s$, 1-deoxy-D-xylulose-5-phosphate synthase; ispH, 4-hydroxy-3-methylbut-2-en-1-yl diphosphate reductase; idi, isopentenyl-diphosphate isomerase; $i d s A$, geranylgeranyl diphosphate synthase; $c r t E$, geranylgeranyl diphosphate synthase; $c r t B$, phytoene synthase; $c r t I$, phytoene desaturase; $c r t E b$, lycopene elongase; $c r t Y_{e l f}$, lycopene $\beta$-cyclase; $x y l B$, xylulokinase; isp $A_{E c}$, farnesyl pyrophosphate synthase from Escherichia coli; PcPS, plant patchoulol synthase from Pogostemon cablin; $x y l A_{X c}$, xylose isomerase from Xanthomonas campestris; $\operatorname{ara} A_{E C}$, arabinose isomerase from E. coli; $\operatorname{araB}_{E C}$, ribulokinase from E. coli; $a r a D_{E C}$, ribulose-5-phosphate-4-epimerase from E. coli; GAP, glycerol aldehyde phosphate; DXP, 1-deoxy-D-xylulose-5-phosphate; HMBPP, 4-hydroxy-3-methylbut-2-enyl diphosphate; IPP, isopentenyl pyrophosphate; DMAPP, dimethylallyl pyrophosphate; FPP, farnesyl pyrophosphate; GGPP, geranylgeranyl pyrophosphate; (b) Carotenogenic genes and operons in C. glutamicum. The major crt operon contains: crtE (cg0723), geranylgeranyl diphosphate synthase; (cg0722); $c r t B$ (cg0721), phytoene synthase; crtI (cg0720), phytoene desaturase; $\operatorname{crtY}_{e}(\mathrm{cg} 0719) ; \operatorname{crt} Y_{f}(\mathrm{cg} 0718) ; \operatorname{crtEb}$ (cg0717), phytoene synthase. The small crt operon contains: crtB2 (cg2672), phytoene synthase; crtI2' (cg2670), non-functional phytoene desaturase; crtI2" (cg2668), non-functional phytoene desaturase. idsA (cg2384), geranylgeranyl diphosphate synthase. 
The deletion of both GGPP synthases genes $i d s A$ and $c r t E$ results in the accumulation of the central terpenoid precursor molecules IPP and DMAPP due to the lack of other short-chain prenyltransferases in C. glutamicum. Heterologous overexpression of ispA from E. coli coding for FPP synthase and overexpression of a codon-optimized PcPS encoding the patchoulol synthase from P. cablin (Uniprot Q49SP3) in this strain enabled patchoulol production from glucose (PAT1) (Figure 1). PAT1 cells even exhibited a distinct earthy odor of the patchouli alcohol under IPTG induction on the agar plate. Cultivation of PAT1 in $20 \mathrm{~mL}$ CGXII with $100 \mathrm{mM}$ glucose produced $0.20 \pm 0.03 \mathrm{mg} \mathrm{L}^{-1}$ patchoulol (concentrations are given based on the total culture medium volume) within $48 \mathrm{~h}$ incubation. $1 \mathrm{mM}$ IPTG was added to the culture medium in the exponential growth phase $(t=5 \mathrm{~h})$ in order to induce plasmid-driven gene expression of the prenyltransferase and terpene synthase genes. At the same time, $2 \mathrm{~mL}$ of dodecane was added as an overlay to capture the volatile product. Interestingly, C. glutamicum PAT1 cells exhibited a colored phenotype. The pigmentation may be due to the formation of (a) C30 carotenoid-like structure(s) under the assumption that endogenous carotenogenic enzymes accept FPP as substrate in the absence of GGPP (Figure 1). Thus, deletion of all carotenogenic genes from the C. glutamicum genome was conducted in order to prevent formation of undesired terpenoid byproducts (see Figure S1). As expected, the corresponding strain PAT2 lacking both crt operons [15] as well as the major GGPP synthase [35] showed the desired white phenotype indicating that carotenoid-like byproducts were no longer accumulated (Figure 1 and Figure S1). The patchoulol titer of PAT2 $\left(0.22 \pm 0.02 \mathrm{mg} \mathrm{L}^{-1}\right)$ remained comparable to that produced by PAT1 (Table 3).

As known from production of other short- and long-chain terpenoids by recombinant C. glutamicum [18,36], precursor supply was expected to limit patchoulol production and therefore was set as a target for further engineering. Overproduction of the first enzyme of the MEP-pathway, Dxs, as well as the isomerase Idi, have been shown to be highly effective for improved terpenoid production both in C. glutamicum $[17,36]$ and E. coli $[37,38]$ due to the generation of increased precursor supply for terpenoid products. Here, plasmid-driven overexpression of endogenous $d x s$ and idiimproved patchoulol production approximately 2-fold (Table 3). The strain PAT3 produced $0.46 \pm 0.07 \mathrm{mg} \mathrm{L}^{-1}$ patchoulol in shake flask cultures within $48 \mathrm{~h}$. The volumetric productivity of $0.23 \pm 0.03 \mathrm{mg} \mathrm{L}^{-1} \mathrm{~d}^{-1}$ is among the highest reported for patchoulol production [10].

Table 3. Patchoulol production from $100 \mathrm{mM}$ glucose in shake flasks $(20 \mathrm{~mL})$ after $48 \mathrm{~h}$. Patchoulol titers and productivity refer to the total culture volume and are represented as mean values and standard deviations of biological triplicates. For comparison wild-type C. glutamicum grew to a biomass concentration of $5.4 \mathrm{~g} \mathrm{~L}^{-1} \mathrm{CDW}$ from $100 \mathrm{mM}$ glucose in the presence of dodecane [17].

\begin{tabular}{|c|c|c|c|}
\hline & PAT1 & PAT2 & РAT3 \\
\hline $\mathrm{CDW}\left[\mathrm{g} \mathrm{L}^{-1}\right]$ & $4.4 \pm 0.6$ & $4.2 \pm 0.6$ & $4.2 \pm 0.7$ \\
\hline Titer $\left[\mathrm{mg} \mathrm{L}^{-1}\right]$ & $0.20 \pm 0.03$ & $0.21 \pm 0.02$ & $0.46 \pm 0.07$ \\
\hline Vol. productivity [mg L ${ }^{-1} \mathrm{~d}^{-1}$ ] & $0.10 \pm 0.01$ & $0.11 \pm 0.01$ & $0.23 \pm 0.03$ \\
\hline
\end{tabular}

\subsection{Patchoulol Production from Alternative Carbon Sources}

In order to test if patchoulol production from C. glutamicum could be conducted in a sustainable manner on carbon sources which do not compete for resources with food and feed production, small scale fermentations of PAT3 were carried out with the pentoses L-arabinose and D-xylose. These pentoses can be derived from agricultural waste products such as wheat or rice straw hydrolysates [29,39]. Since the PAT3 strain is not able to grow on either substrate, metabolic engineering for utilization of arabinose and xylose was performed. First, plasmid-driven overproduction of arabinose isomerase, ribulokinase and ribulose-5-phosphate-4-epimerase encoded by the araBAD operon from E. coli enabled C. glutamicum growth and the production of patchoulol. These enzymes convert arabinose to xylulose 5-phosphate, a central intermediate of the pentose phosphate pathway. Second, plasmid-driven overproduction of xylose isomerase and xylulokinase encoded by $x y l A$ from 
X. campestris and $x y l B$ from $C$. glutamicum, respectively, allowed phosphorylation and isomerization of the pentose sugar to xylulose 5-phosphate [29].

As shown in Figure 2 patchoulol production was possible from the cultivation of engineered C. glutamicum on the pentoses arabinose and xylose. The control strain PAT3 (pEKEx3) produced $0.41 \pm 0.08 \mathrm{mg} \mathrm{L}^{-1}$ patchoulol from $10 \mathrm{~g} \mathrm{~L}^{-1}$ glucose. The strains PAT3 (pEKEx3_araBAD) and PAT3 (pEKEx3_xylAB) produced $0.15 \pm 0.04 \mathrm{mg} \mathrm{L}^{-1}$ and $0.23 \pm \mathrm{mg} \mathrm{L}^{-1}$ patchoulol on the basis of $10 \mathrm{~g} \mathrm{~L}^{-1}$ of the respective pentose sugar. The observed differences in patchoulol titers may reflect that glucose can be catabolized in glycolysis and/or the oxidative pentose phosphate pathway while arabinose and xylose catabolism proceeds via the oxidative pentose pathway. To comprehend the differences of growth and production between the substrates glucose, arabinose, and xylose a full carbon-13 based labelling flux metabolic analysis is needed, however, the data depicted in Figure 2 provide a proof-of-concept that patchoulol production from xylose and arabinose is possible.

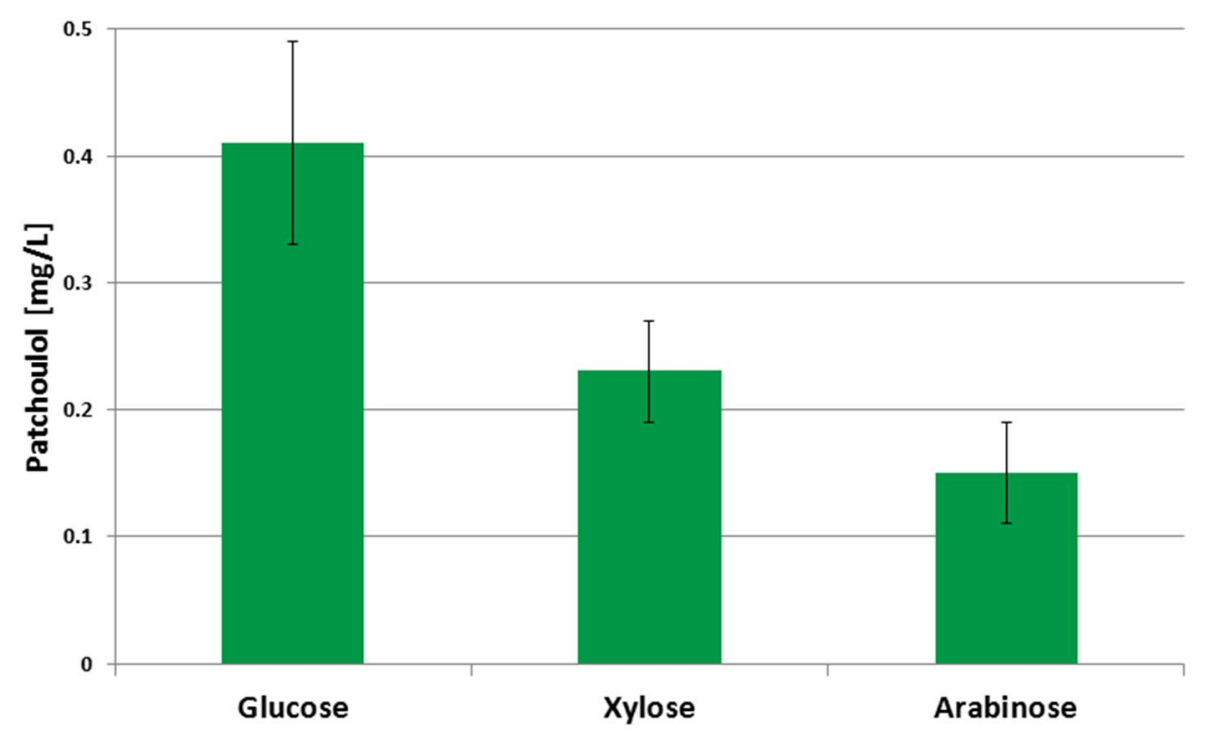

Figure 2. Patchoulol production from alternative carbon sources in $20 \mathrm{~mL}$ shake flasks after $48 \mathrm{~h}$. Patchoulol titers from $10 \mathrm{~g} \mathrm{~L}^{-1}$ of glucose, xylose, and arabinose are shown as mean and arithmetic deviation from the mean from biological duplicates. Cultivation was performed in CGXII minimal medium with $1 \mathrm{mM}$ IPTG and $10 \%(v / v)$ of dodecane.

\subsection{Batch Fermentation for Patchoulol Production}

Since the volumetric patchoulol productivity of PAT3 was among the highest reported [10], patchoulol production was tested in bioreactors in order to investigate stability and reliability of the process. First, PAT3 was cultivated in a $2 \mathrm{~L}$ fermenter in batch mode with $40 \mathrm{~g} \mathrm{~L}^{-1}$ of glucose monohydrate. Product concentration was monitored over time (Figure 3). The relative dissolved oxygen saturation $(r D O S)$ was kept constant at $60 \%$ by regulation of the rotary frequency of the stirrer. A maximal titer of $18 \mathrm{mg} \mathrm{L}^{-1}$ patchoulol $(\mathrm{t}=76 \mathrm{~h})$ was achieved in the two-phase culture system containing $2 \mathrm{~L}$ culture and $200 \mathrm{~mL}$ dodecane overlay when dodecane and $1 \mathrm{mM}$ IPTG were added in the early exponential growth phase $5 \mathrm{~h}$ after inoculation (at $O D \sim 10$ ). Biomass concentration (cell dry weight) was calculated on the basis of the optical density $(600 \mathrm{~nm})$. Measurements of the optical density and corresponding biomass were adjusted after the addition of dodecane due to emulsification. The maximal volumetric productivity was reached after $53 \mathrm{~h}$ with around $6.4 \mathrm{mg} \mathrm{L}^{-1} \mathrm{~d}^{-1}$, corresponding a current titer of $\sim 14 \mathrm{mg} \mathrm{L}^{-1}$ patchoulol in the culture medium (Figure 3). The patchoulol titer represents an improvement by a factor $\sim 30$ in comparison to the shake flasks experiments in $20 \mathrm{~mL}$ scale. 


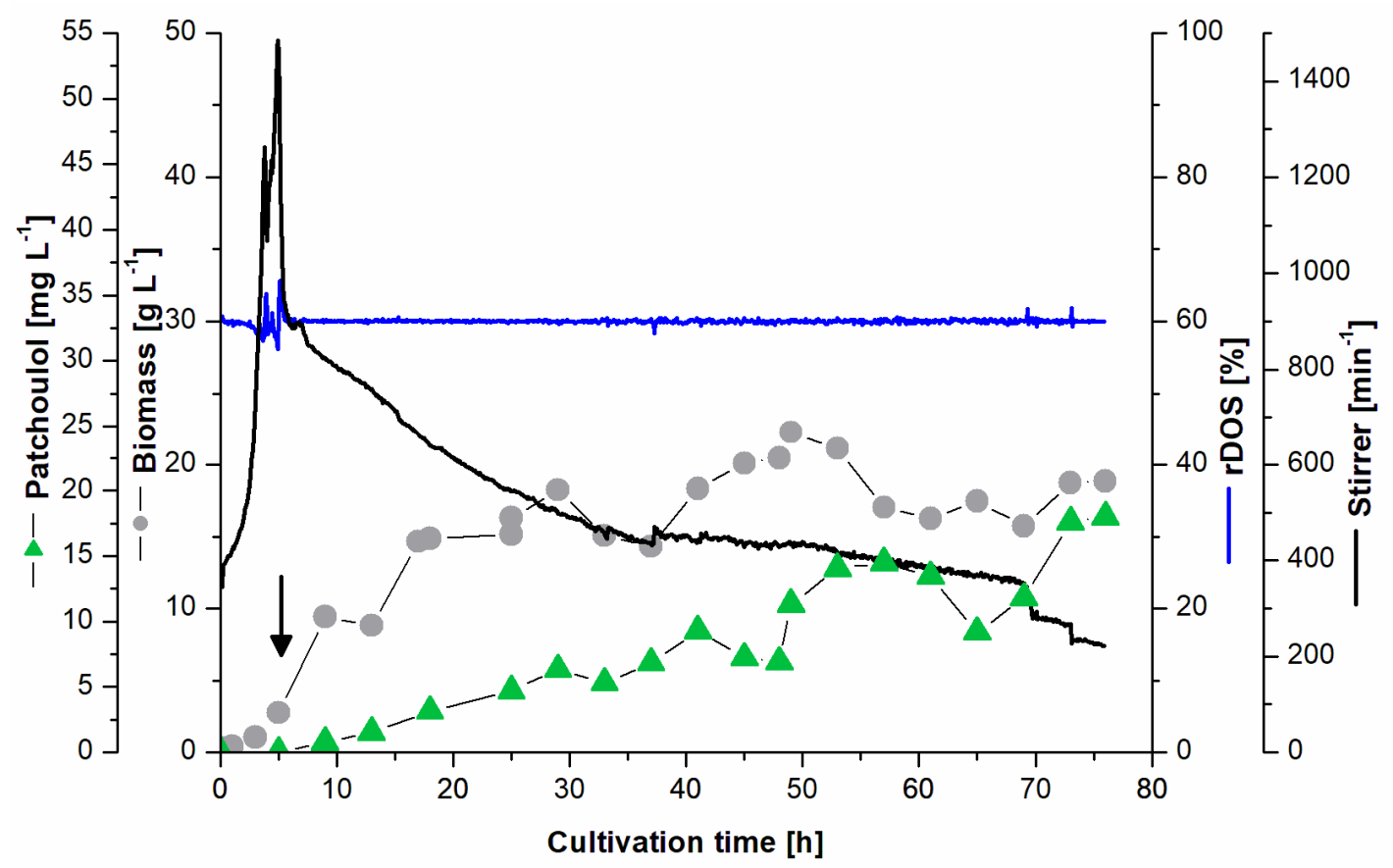

Figure 3. Batch fermentation for patchoulol production. PAT3 was cultivated in batch mode containing i.a. $40 \mathrm{~g} \mathrm{~L}^{-1}$ glucose monohydrate over $80 \mathrm{~h}$. Patchoulol titer is indicated with green triangles $\left(\mathrm{mg} \mathrm{L}^{-1}\right)$; biomass concentration $(\mathrm{CDW})$ is indicated in grey circles $\left(\mathrm{g} \mathrm{L}^{-1}\right)$, relative dissolved oxygen saturation is indicated in blue ( $r D O S \%$ ) and the stirrer frequency is shown in black $\left(\mathrm{min}^{-1}\right)$.

\subsection{Fed-Batch Fermentation for Patchoulol Production}

Batch fermentation here resulted in a 30-fold improved patchoulol titer over shake flask experiments, which prompted us to investigate fed-batch mode fermentation with PAT3 in a $2 \mathrm{~L}$ fermenter. The batch phase was performed as described previously in complex medium supplemented with $40 \mathrm{~g} \mathrm{~L}^{-1}$ glucose monohydrate as primary carbon and energy source. Plasmid-born gene expression was induced by the addition of $1 \mathrm{mM}$ IPTG after $5 \mathrm{~h}$ of cultivation in order to prevent accumulation of the toxic precursor molecules DMAPP and IPP. Dodecane was added in the feeding phase, $25 \mathrm{~h}$ after inoculation at an $O D \sim 75$ to capture the volatile patchoulol. The feeding solution contained $300 \mathrm{~g} \mathrm{~L}^{-1}$ glucose monohydrate and yeast extract as nitrogen source. Feeding was controlled via the $r D O S$ profile and started $\sim 10 \mathrm{~h}$ after inoculation when the $r D O S$ reached $60 \%$. A total feed amount of $\sim 1000$ g medium ( $\sim 220$ g glucose) was applied over the whole process. As a result, a high biomass titer of $\sim 30 \mathrm{~g} \mathrm{~L}^{-1} \mathrm{CDW}$ was reached (Figure 4). The patchoulol titer of $\sim 50 \mathrm{mg} \mathrm{L}^{-1}$ (in relation to the culture volume) was reached around $76 \mathrm{~h}$ after inoculation, corresponding to a volumetric productivity of $\sim 15 \mathrm{mg} \mathrm{L}^{-1} \mathrm{~d}^{-1}$. The maximal volumetric productivity of $\sim 18 \mathrm{mg} \mathrm{L}^{-1} \mathrm{~d}^{-1}$ was reached in the feeding phase of the two-phase culture system $(t=53 \mathrm{~h})$. The titer of patchoulol in the culture medium reached $60 \mathrm{mg} \mathrm{L}^{-1}$ at $142 \mathrm{~h}$ of fermentation (data not shown). 


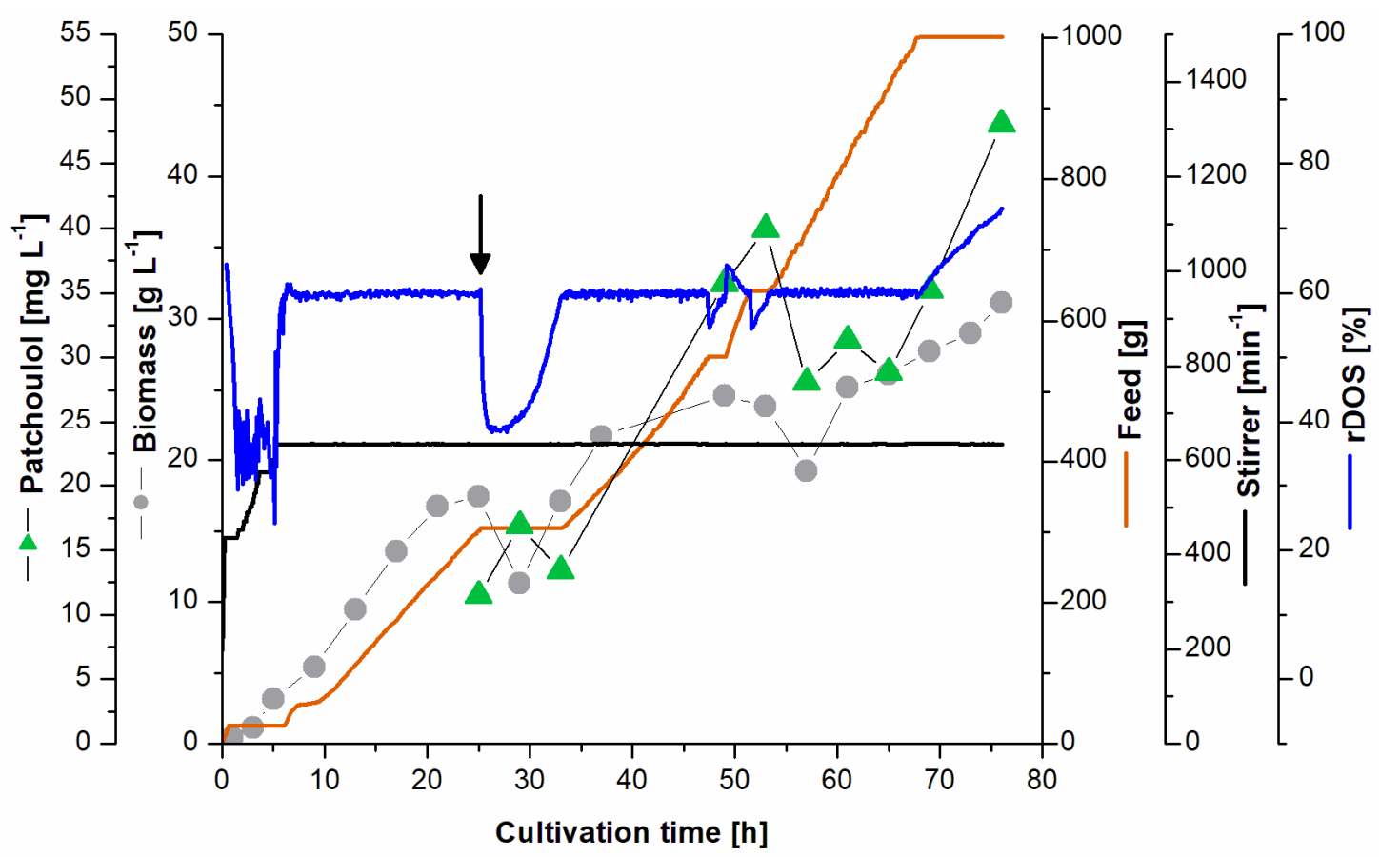

Figure 4. Fed-Batch fermentation for patchoulol production. PAT3 was cultivated in fed-batch mode containing i.a. $40 \mathrm{~g} \mathrm{~L}^{-1}$ glucose monohydrate over $80 \mathrm{~h}$. Patchoulol titer is indicated with green triangles $\left(\mathrm{mg} \mathrm{L}^{-1}\right)$; biomass concentration $(\mathrm{CDW})$ in grey circles $\left(\mathrm{g} \mathrm{L}^{-1}\right)$, feed in orange ( $\mathrm{g}$ of medium), relative dissolved oxygen saturation is indicated in blue $(r D O S \%)$, and the stirrer frequency is shown in black $\left(\min ^{-1}\right)$.

\section{Discussion}

In this work, patchoulol production by C. glutamicum, the microbial cell factory for the million-ton-scale production of amino acids [14], was demonstrated (see Figure S2). Strain engineering addressed heterologous overproduction of FPP synthase, overproduction of codon-optimized plant patchoulol synthase (PcPS), prevention of terpenoid byproducts, increased flux through the MEP-pathway and balancing of the DMAPP to IPP ratio. To the best of our knowledge, the titer of $60 \mathrm{mg} \mathrm{L}^{-1}$ and the volumetric productivity of $18 \mathrm{mg} \mathrm{L}^{-1} \mathrm{~d}^{-1}$ achieved in $2 \mathrm{~L}$ bioreactor cultures are the highest patchoulol yields reported to date for microbial fermentation. For comparison, the highest reported titers and volumetric productivities obtained with phototrophic hosts were $\sim 1 \mathrm{mg} \mathrm{L}^{-1}$ and $\sim 0.23 \mathrm{mg} \mathrm{L}^{-1} \mathrm{~d}^{-1}$, respectively, [10].

First, heterologous overproduction of FPP synthase and the plant patchoulol synthase were combined in PAT1, which resulted in the formation of patchoulol. However, overproduction of FPP in the presence of endogenous carotenogenic enzymes $\mathrm{CrtB}$ and $\mathrm{CrtI}$, but in the absence of their cognate substrate GGPP, resulted in the accumulation of a carotenoid-like pigment indicating the native enzymes have some affinity for the produced FPP. It is conceivable that C30 carotenoids, for example, $4,4^{\prime}$-diapolycopene have been formed. Thus, deletion of the carotenogenic operons and genes in the wild-type background strain were performed to avoid accumulation of untargeted terpenoid by-products. Although deletion of the carotenogenic genes did not improve patchoulol production, the white cells of PAT2 and PAT3 may be favorable for patchoulol downstream processing. Usually, clear products are preferred for cosmetic ingredients and extraction of colored terpenoid pigment by-products can thus be avoided in these strains.

Patchoulol production could be improved by 2-fold due to an improved flux through the MEP-pathway, mediated by the overexpression of $d x s$, and an improved balance of the precursors DMAPP and IPP was achieved by the overexpression of $i d i$. The strain PAT3 produced $\sim 0.5 \mathrm{mg} \mathrm{L}^{-1}$ 
patchoulol in $20 \mathrm{~mL}$ scale from $100 \mathrm{mM}$ glucose. The MEP-pathway is supposed to be heavily regulated at many levels $[1,40]$ and overexpression of both $d x s$ and $i d i$ were shown to be beneficial for improving terpenoid production from several organisms, including E. coli and C. glutamicum. Indeed, $d x$ s and idi, are considered the main rate-limiting steps within the MEP pathway [37,41]. While overproduction of Dxs enhances the flow through the MEP pathway to ultimately produce more IPP and DMAPP, the cause for the beneficial role of Idi overexpression, and its effect on IPP and DMAPP ratios, is still under investigation. In E. coli, overproduction of Idi led to a shift of the natural IPP and DMAPP ratio of 5:1 [42] towards DMAPP, thus allowing for the production of more FPP since it is made by two molecules of IPP and one molecule of DMAPP [37].

Production titers of the sesquiterpene (+)-valencene in C. glutamicum were shown to be improved by the use of caged-IPTG, allowing photo-induced production onset with UV light, compared to conventional IPTG in microtiter-scale production experiments [18]. Whether this effect can be transferred to patchoulol production in flask or even bioreactor scale experiments needs to be evaluated. However, the relatively high price of caged-IPTG compared to IPTG, makes utilization in larger scales not feasible [18].

After establishment of patchoulol production from C. glutamicum in small scale ( $20 \mathrm{~mL})$, scale up was conducted. Here, the 100 -fold increase in scale from $20 \mathrm{~mL}$ to $2 \mathrm{~L}$ was successfully performed in a bioreactor. A 30-fold increased patchoulol titer in comparison to shake flasks was observed. The strong improvement is likely due to improved oxygen input and saturation in the bioreactor compared to shake flasks and/or the consistency of $\mathrm{pH}$ in the controlled reactor. A beneficial effect due to improved dodecane mixing with the microbial culture is also a likely factor in the observed product titers. Dodecane captures volatile hydrophobic compounds and also supports the release or extraction of these compounds from hydrophobic biological membranes [43]. In the fed-batch fermentation, a patchoulol titer of $\sim 60 \mathrm{mg} \mathrm{L}^{-1}$ was achieved within $142 \mathrm{~h}$ of cultivation, corresponding to a 130-fold increase in productivity in comparison to the small-scale flask fermentation and an about 4 -fold increase compared to the batch-mode bioreactor culture. The significant drop in the relative dissolved oxygen $(r D O S)$ at $25 \mathrm{~h}$ can be explained with coalescence due to dodecane application. With a volumetric productivity of $\sim 18 \mathrm{mg} \mathrm{L}^{-1} \mathrm{~d}^{-1}$ the production process presented here is superior to other production systems in respect to maximal titers and volumetric productivities. Both batch and fed-batch fermentations conducted here had maximal volumetric productivities around $53 \mathrm{~h}$ after inoculation, with 6.4 and $18 \mathrm{mg} \mathrm{L}^{-1} \mathrm{~d}^{-1}$, respectively. In this work, patchoulol was captured in a dodecane phase, allowing a first separation of the product from the cell fraction. Dodecane as a linear petrochemical hydrocarbon is considered a green solvent from the cluster 2 of the chemometric solvent selection guide with a high confidence level [44]. Alternatively, patchoulol capture is possible with isopropyl myristate, which is classified as a green solvent [45]. Both in batch and fed-batch fermentations, plasmid expression was induced $5 \mathrm{~h}$ after inoculation. Since the strain PAT3 overproduces the terpenoid precursor molecules DMAPP and IPP, accumulation of these toxic compounds might affect the cells negatively as has been shown for Bacillus subtilis and E. coli [46].

Interestingly, PAT3 cells cultivated under fed-batch mode produced additional sequiterpenes. According to the GC-MS library search, azulene and caryophyllene. However, the peak intensities of these products were much lower and product formation occurred only in the late stationary phase (data not shown). The promiscuity of the used patchoulol synthase from P. cablin was already mentioned in literature with a least 13 additional sequiterpene products [5]. A rough comparison of the in vitro enzymatic activity of $\sim 0.02 \mathrm{unit} \mathrm{mg}^{-1}$, corresponding to $213,000 \mu \mathrm{g} \mathrm{CDW}^{-1} \mathrm{~d}^{-1}[7,47]$ of purified PcPS is in accordance with the volumetric productivity $\sim 15 \mathrm{mg} \mathrm{L}^{-1} \mathrm{~d}^{-1}, 1000 \mu \mathrm{g} \mathrm{CDW}^{-1}$ $\mathrm{d}^{-1}$, of this study under the assumption that approximately $0.3 \%$ of the cellular protein of the producer strain is PcPS.

Sequiterpenes are interesting products and their heterologous production has been in established in several microorganisms. The biofuel component farnesene [48] can be produced with volumetric productivities of up to $16.9 \mathrm{~g} \mathrm{~L}^{-1} \mathrm{~d}^{-1}$ and a maximum titer of $104.3 \mathrm{~g} \mathrm{~L}^{-1}$ [49], which is one of the 
highest reported terpenoid titers so far. Heterologous production of the anti-malaria drug precursor artemisinic acid is a prominent example for a high pricing terpenoid that was established in both eukaryotic and prokaryotic host organisms, S. cerevisiae and E. coli, respectively. A titer of $27.4 \mathrm{~g} \mathrm{~L}^{-1}$ amorphadiene is one of the highest reported for E. coli whereas functionalization of this sesquiterpene by a plant-based P450 enzyme enabled production of $105 \mathrm{mg} \mathrm{L}^{-1}$ artemisinic acid [50]. To the best of our knowledge, artemisinic acid production reached $25 \mathrm{~g} \mathrm{~L}^{-1}$ with yeast, which is the highest reported to date [51]. These overproducing strains share intensive metabolic engineering, especially the expression of the de-regulated MEV-pathway, which in bacterial hosts has been demonstrated to be a powerful strategy for boosting overall terpenoid yields and could also be a suitable target for C. glutamicum. Establishment of this second precursor pathway might result in a significant increase of DMAPP and IPP production as the heterologous MEV-pathway is not expected to be regulated in C. glutamicum. In the terpenoid production strains mentioned above genes have been integrated and expressed from chromosomal locations using strong constitutive natural or synthetic promoters rather than from IPTG inducible plasmids. This increased genetic stability as well as gene expression represent a valuable strategy to further improve the patchoulol producing C. glutamicum strains described here. Since a number of terpenes inhibit bacterial growth further strain engineering may be guided, e.g., by RNAseq analysis of gene expression +/ - patchoulol, to improve patchouli production if patchoulol inhibits growth. This may also be relevant to adjust the fermentation process.

\section{Conclusions}

Metabolic engineering of C. glutamicum led, to the best of our knowledge, to the highest patchoulol titers (up $60 \mathrm{mg} \mathrm{L}^{-1}$ ) and volumetric productivities (up $18 \mathrm{mg} \mathrm{L}^{-1} \mathrm{~d}^{-1}$ ) of microbial fermentation reported to date. Production of patchoulol by recombinant $C$. glutamicum from substrates not competing for use in human or animal nutrition such as the pentose sugars L-arabinose and D-xylose was enabled. Patchoulol production from C. glutamicum was successfully demonstrated in batch and fed-batch bioreactor set-ups with two-phase organic solvent overlay for capture of the semi-volatile sesquiterpenoid product.

Supplementary Materials: The following are available online at http:/ / www.mdpi.com/2073-4425/9/4/219/ s1, Figure S1: Phenotypes of patchoulol-overproducing PAT1 and PAT2 strains, Figure S2: GC-MS analysis of patchoulol.

Acknowledgments: P.P.W. and V.F.W. wish to dedicate this publication to Bernhard J. Eikmanns on the occasion of his 60th birthday. We thank Carina Prell, Christopher Whitford and Dominik Andrae for support during the liter scale fermentations and Susanne Götker for cultivations on alternative carbon sources.

Author Contributions: N.A.H., O.K. and V.F.W. conceived and designed the experiments; N.A.H. constructed, cultivated and analysed C. glutamicum strains; J.W. and N.A.H. analysed product formation; J.M.R performed fermentation experiments and evaluated data; N.A.H., T.B. and J.F. constructed plasmids; V.F.W. and O.K. contributed reagents/materials/analysis tools; N.A.H., K.J.L. and P.P.-W. drafted the manuscript and V.F.W. finalised the manuscript. All authors agreed to the final version.

Conflicts of Interest: The authors declare no conflict of interest. The founding sponsors had no role in the design of the study; in the collection, analyses, or interpretation of data; in the writing of the manuscript, and in the decision to publish the results.

\section{References}

1. Frank, A.; Groll, M. The methylerythritol phosphate pathway to isoprenoids. Chem. Rev. 2017, 117, 5675-5703. [CrossRef] [PubMed]

2. Perez-Gil, J.; Rodriguez-Concepcion, M. Metabolic plasticity for isoprenoid biosynthesis in bacteria. Biochem. J. 2013, 452, 19-25. [CrossRef] [PubMed]

3. Bohlmann, J.; Keeling, C.I. Terpenoid biomaterials. Plant J. 2008, 54, 656-669. [CrossRef] [PubMed]

4. Singh, M.; Sharma, S.; Ramesh, S. Herbage, oil yield and oil quality of patchouli [Pogostemon cablin (blanco) benth.] influenced by irrigation, organic mulch and nitrogen application in semi-arid tropical climate. Ind. Crops Prod. 2002, 16, 101-107. [CrossRef] 
5. Deguerry, F.; Pastore, L.; Wu, S.; Clark, A.; Chappell, J.; Schalk, M. The diverse sesquiterpene profile of patchouli, Pogostemon cablin, is correlated with a limited number of sesquiterpene synthases. Arch. Biochem. Biophys. 2006, 454, 123-136. [CrossRef] [PubMed]

6. Kusuma, H.S.; Mahfud, M. The extraction of essential oils from patchouli leaves (Pogostemon cablin benth) using a microwave air-hydrodistillation method as a new green technique. RSC Adv. 2017, 7, 1336-1347. [CrossRef]

7. Munck, S.L.; Croteau, R. Purification and characterization of the sesquiterpene cyclase patchoulol synthase from Pogostemon cablin. Arch. Biochem. Biophys. 1990, 282, 58-64. [CrossRef]

8. Gruchattka, E.; Hadicke, O.; Klamt, S.; Schutz, V.; Kayser, O. In silico profiling of Escherichia coli and Saccharomyces cerevisiae as terpenoid factories. Microb. Cell Fact. 2013, 12, 84. [CrossRef] [PubMed]

9. Zhan, X.; Zhang, Y.H.; Chen, D.F.; Simonsen, H.T. Metabolic engineering of the moss Physcomitrella patens to produce the sesquiterpenoids patchoulol and alpha/beta-santalene. Front. Plant Sci. 2014, 5, 636. [CrossRef] [PubMed]

10. Lauersen, K.J.; Baier, T.; Wichmann, J.; Wordenweber, R.; Mussgnug, J.H.; Hubner, W.; Huser, T.; Kruse, O. Efficient phototrophic production of a high-value sesquiterpenoid from the eukaryotic microalga Chlamydomonas reinhardtii. Metab. Eng. 2016, 38, 331-343. [CrossRef] [PubMed]

11. Riesenberg, D.; Guthke, R. High-cell-density cultivation of microorganisms. Appl. Microbiol. Biotechnol. 1999, 51, 422-430. [CrossRef] [PubMed]

12. Pfeifer, E.; Gatgens, C.; Polen, T.; Frunzke, J. Adaptive laboratory evolution of Corynebacterium glutamicum towards higher growth rates on glucose minimal medium. Sci. Rep. 2017, 7, 16780. [CrossRef] [PubMed]

13. Heider, S.A.; Wendisch, V.F. Engineering microbial cell factories: Metabolic engineering of Corynebacterium glutamicum with a focus on non-natural products. Biotechnol. J. 2015, 10, 1170-1184. [CrossRef] [PubMed]

14. Lee, J.H.; Wendisch, V.F. Production of amino acids-Genetic and metabolic engineering approaches. Bioresour. Technol. 2017, 245, 1575-1587. [CrossRef] [PubMed]

15. Heider, S.A.; Peters-Wendisch, P.; Wendisch, V.F. Carotenoid biosynthesis and overproduction in Corynebacterium glutamicum. BMC Microbiol. 2012, 12, 198. [CrossRef] [PubMed]

16. Krubasik, P.; Takaichi, S.; Maoka, T.; Kobayashi, M.; Masamoto, K.; Sandmann, G. Detailed biosynthetic pathway to decaprenoxanthin diglucoside in Corynebacterium glutamicum and identification of novel intermediates. Arch. Microbiol. 2001, 176, 217-223. [CrossRef] [PubMed]

17. Frohwitter, J.; Heider, S.A.; Peters-Wendisch, P.; Beekwilder, J.; Wendisch, V.F. Production of the sesquiterpene (+)-valencene by metabolically engineered Corynebacterium glutamicum. J. Biotechnol. 2014, 191, $205-213$. [CrossRef] [PubMed]

18. Binder, D.; Frohwitter, J.; Mahr, R.; Bier, C.; Grunberger, A.; Loeschcke, A.; Peters-Wendisch, P.; Kohlheyer, D.; Pietruszka, J.; Frunzke, J.; et al. Light-controlled cell factories: Employing photocaged isopropyl-beta-D-thiogalactopyranoside for light-mediated optimization of lac promoter-based gene expression and (+)-valencene biosynthesis in Corynebacterium glutamicum. Appl. Environ. Microbiol. 2016, 82, 6141-6149. [CrossRef] [PubMed]

19. Heider, S.A.; Wolf, N.; Hofemeier, A.; Peters-Wendisch, P.; Wendisch, V.F. Optimization of the IPP precursor supply for the production of lycopene, decaprenoxanthin and astaxanthin by Corynebacterium glutamicum. Front. Bioeng. Biotechnol. 2014, 2, 28. [CrossRef] [PubMed]

20. Heider, S.A.; Peters-Wendisch, P.; Netzer, R.; Stafnes, M.; Brautaset, T.; Wendisch, V.F. Production and glucosylation of C50 and C40 carotenoids by metabolically engineered Corynebacterium glutamicum. Appl. Microbiol. Biotechnol. 2014, 98, 1223-1235. [CrossRef] [PubMed]

21. Henke, N.A.; Heider, S.A.E.; Hannibal, S.; Wendisch, V.F.; Peters-Wendisch, P. Isoprenoid pyrophosphate-dependent transcriptional regulation of carotenogenesis in Corynebacterium glutamicum. Front. Microbiol. 2017, 8, 633. [CrossRef] [PubMed]

22. Taniguchi, H.; Henke, N.A.; Heider, S.A.E.; Wendisch, V.F. Overexpression of the primary sigma factor gene sigA improved carotenoid production by Corynebacterium glutamicum: Application to production of $\beta$-carotene and the non-native linear C50 carotenoid bisanhydrobacterioruberin. Metab. Eng. Commun. 2017, 4, 1-11. [CrossRef] [PubMed]

23. Henke, N.A.; Wiebe, D.; Pérez-García, F.; Peters-Wendisch, P.; Wendisch, V.F. Coproduction of cell-bound and secreted value-added compounds: Simultaneous production of carotenoids and amino acids by Corynebacterium glutamicum. Bioresour. Technol. 2018, 722-752. [CrossRef] 
24. Abe, S.; Takayarna, K.; Kinoshita, S. Taxonomical studies on glutamic acid producing bacteria. J. Gen. Appl. Microbiol. 1967, 13, 279-301. [CrossRef]

25. Eggeling, L.; Bott, M. Handbook of Corynebacterium glutamicum; CRC Press Taylor \& Francis Group: Boca Raton, FL, USA, 2005.

26. Hanahan, D. Studies on transformation of Escherichia coli with plasmids. J. Mol. Biol. 1983, 166, 557-580. [CrossRef]

27. Kirchner, O.; Tauch, A. Tools for genetic engineering in the amino acid-producing bacterium Corynebacterium glutamicum. J. Biotechnol. 2003, 104, 287-299. [CrossRef]

28. Stansen, C.; Uy, D.; Delaunay, S.; Eggeling, L.; Goergen, J.L.; Wendisch, V.F. Characterization of a Corynebacterium glutamicum lactate utilization operon induced during temperature-triggered glutamate production. Appl. Environ. Microbiol. 2005, 71, 5920-5928. [CrossRef] [PubMed]

29. Meiswinkel, T.M.; Gopinath, V.; Lindner, S.N.; Nampoothiri, K.M.; Wendisch, V.F. Accelerated pentose utilization by Corynebacterium glutamicum for accelerated production of lysine, glutamate, ornithine and putrescine. Microb. Biotechnol. 2013, 6, 131-140. [CrossRef] [PubMed]

30. Peters-Wendisch, P.G.; Schiel, B.; Wendisch, V.F.; Katsoulidis, E.; Mockel, B.; Sahm, H.; Eikmanns, B.J. Pyruvate carboxylase is a major bottleneck for glutamate and lysine production by Corynebacterium glutamicum. J. Mol. Microbiol. Biotechnol. 2001, 3, 295-300. [PubMed]

31. Schäfer, A.; Tauch, A.; Jäger, W.; Kalinowski, J.; Thierbach, G.; Puhler, A. Small mobilizable multi-purpose cloning vectors derived from the Escherichia coli plasmids pk18 and pk19: Selection of defined deletions in the chromosome of Corynebacterium glutamicum. Gene 1994, 145, 69-73. [CrossRef]

32. Gibson, D.G.; Young, L.; Chuang, R.Y.; Venter, J.C.; Hutchison, C.A., III; Smith, H.O. Enzymatic assembly of DNA molecules up to several hundred kilobases. Nat. Methods 2009, 6, 343-345. [CrossRef] [PubMed]

33. Sambrook, J.; Russell, D. Molecular Cloning: A Laboratory Manual, 3rd ed.; Cold Spring Harbor Laboratoy Press: Cold Spring Harbor, NY, USA, 2001.

34. Van der Rest, M.E.; Lange, C.; Molenaar, D. A heat shock following electroporation induces highly efficient transformation of Corynebacterium glutamicum with xenogeneic plasmid DNA. Appl. Microbiol. Biotechnol. 1999, 52, 541-545. [CrossRef] [PubMed]

35. Heider, S.A.; Peters-Wendisch, P.; Beekwilder, J.; Wendisch, V.F. IdsA is the major geranylgeranyl pyrophosphate synthase involved in carotenogenesis in Corynebacterium glutamicum. FEBS J. 2014, 281, 4906-4920. [CrossRef] [PubMed]

36. Henke, N.A.; Heider, S.A.; Peters-Wendisch, P.; Wendisch, V.F. Production of the marine carotenoid astaxanthin by metabolically engineered Corynebacterium glutamicum. Mar. Drugs 2016, 14, 124. [CrossRef] [PubMed]

37. Lv, X.; Xu, H.; Yu, H. Significantly enhanced production of isoprene by ordered coexpression of genes $d x s$, dxr, and idi in Escherichia coli. Appl. Microbiol. Biotechnol. 2013, 97, 2357-2365. [CrossRef] [PubMed]

38. Lv, X.; Gu, J.; Wang, F.; Xie, W.; Liu, M.; Ye, L.; Yu, H. Combinatorial pathway optimization in Escherichia coli by directed co-evolution of rate-limiting enzymes and modular pathway engineering. Biotechnol. Bioeng. 2016, 113, 2661-2669. [CrossRef] [PubMed]

39. Gopinath, V.; Meiswinkel, T.M.; Wendisch, V.F.; Nampoothiri, K.M. Amino acid production from rice straw and wheat bran hydrolysates by recombinant pentose-utilizing Corynebacterium glutamicum. Appl. Microbiol. Biotechnol. 2011, 92, 985-996. [CrossRef] [PubMed]

40. Schempp, F.M.; Drummond, L.; Buchhaupt, M.; Schrader, J. Microbial cell factories for the production of terpenoid flavor and fragrance compounds. J. Agric. Food Chem. 2018, 66, 2247-2258. [CrossRef] [PubMed]

41. Kim, S.W.; Keasling, J.D. Metabolic engineering of the nonmevalonate isopentenyl diphosphate synthesis pathway in Escherichia coli enhances lycopene production. Biotechnol. Bioeng. 2001, 72, 408-415. [CrossRef]

42. Xiao, Y.; Zhao, Z.K.; Liu, P. Mechanistic studies of IspH in the deoxyxylulose phosphate pathway: Heterolytic c-o bond cleavage at C4 position. J. Am. Chem. Soc. 2008, 130, 2164-2165. [CrossRef] [PubMed]

43. Gruchattka, E.; Kayser, O. In vivo validation of in silico predicted metabolic engineering strategies in yeast: Disruption of $\alpha$-ketoglutarate dehydrogenase and expression of ATP-citrate lyase for terpenoid production. PLoS ONE 2015, 10, e0144981. [CrossRef] [PubMed]

44. Byrne, F.P.; Jin, S.; Paggiola, G.; Petchey, T.H.M.; Clark, J.H.; Farmer, T.J.; Hunt, A.J.; Robert McElroy, C.; Sherwood, J. Tools and techniques for solvent selection: Green solvent selection guides. Sustain. Chem. Process. 2016, 4, 7. [CrossRef] 
45. Muniglia, L.; Claisse, N.; Baudelet, P.-H.; Ricochon, G. Alternative solvents for natural products extraction. In Green Chemistry and Sustainable Technology; Chemat, F., Vian, A.M., Eds.; Enzymatic Aqueous Extraction (EAE); Springer: Berlin, Germany, 2014; Volume 8, pp. 167-204.

46. Sivy, T.L.; Fall, R.; Rosenstiel, T.N. Evidence of isoprenoid precursor toxicity in Bacillus subtilis. Biosci. Biotechnol. Biochem. 2011, 75, 2376-2383. [CrossRef] [PubMed]

47. Frister, T.; Hartwig, S.; Alemdar, S.; Schnatz, K.; Thons, L.; Scheper, T.; Beutel, S. Characterisation of a recombinant patchoulol synthase variant for biocatalytic production of terpenes. Appl. Biochem. Biotechnol. 2015, 176, 2185-2201. [CrossRef] [PubMed]

48. George, K.W.; Alonso-Gutierrez, J.; Keasling, J.D.; Lee, T.S. Isoprenoid drugs, biofuels, and chemicals-artemisinin, farnesene, and beyond. Adv. Biochem. Eng. Biotechnol. 2015, 148, 355-389. [PubMed]

49. Pray, T.; Biomass R\&D Technical Advisory Committee: Drop-in Fuels Panel. Amyris. 2010. Available online: https:/ / www.biomassboard.gov/pdfs/biomass_tac_todd_pray_09_29_2010.pdf (accessed on 9 April 2018).

50. Tsuruta, H.; Paddon, C.J.; Eng, D.; Lenihan, J.R.; Horning, T.; Anthony, L.C.; Regentin, R.; Keasling, J.D.; Renninger, N.S.; Newman, J.D. High-level production of amorpha-4,11-diene, a precursor of the antimalarial agent artemisinin, in Escherichia coli. PLoS ONE 2009, 4, e4489. [CrossRef] [PubMed]

51. Paddon, C.J.; Keasling, J.D. Semi-synthetic artemisinin: A model for the use of synthetic biology in pharmaceutical development. Nat. Rev. Microbiol. 2014, 12, 355-367. [CrossRef] [PubMed]

(c) 2018 by the authors. Licensee MDPI, Basel, Switzerland. This article is an open access article distributed under the terms and conditions of the Creative Commons Attribution (CC BY) license (http://creativecommons.org/licenses/by/4.0/). 